\title{
Developing soft skills for sustainable development in environmental engineering students through foreign language learning
}

\author{
Lyudmila Korolyova ${ }^{1, *}$, Elena Voyakina $^{1}$, and Laula Zherebayeva $^{2}$ \\ ${ }^{1}$ Tambov State Technical University, 392000 Tambov, Russia \\ ${ }^{2}$ Maltepe University, Istanbul, Turkey
}

\begin{abstract}
The paper focuses on education for sustainable development (ESD) as an integral part of the sustainable development program with its main principles defined by UNESCO. The key competencies that must be developed in accordance with ESD are outlined. Learning a foreign language is considered from the point of view of its contribution to the process of attaining ESD goals in general and developing soft skills in environmental engineering students in particular that is closely connected with students' willingness to communicate (WTC) and integrated with their expectations. The research is done on learners' beliefs and expectations concerning studying a foreign language at the beginning of the academic year in order to choose the most appropriate teaching strategies for developing soft skills, WTC in L2 within the framework of ESD.
\end{abstract}

\section{Introduction}

The issue of sustainable development and its role in the modern world has been of great interest recently. The concept was defined in 1987 by the Brundtland Commission as "development that meets the needs of the present without compromising the ability of future generations to meet their own needs" [1]. Elaine Nevin underlines that development is essential for satisfying human needs and improving the quality of life but it should not prevent the natural environment from meeting needs of present and future generations [2]. The term covers three interacting spheres such as society, environment and economy. Moreover, it is closely connected with the notion "sustainability". The main difference between them is that the latter is considered to be a long-term goal whereas the concept "sustainable development" includes various processes which may help to achieve sustainability (sustainable agriculture and forestry, production and consumption, good government, research and technology transfer etc.). Among them education is distinguished [3].

\footnotetext{
* Corresponding author: lyu-korolyova@yandex.ru
} 
It should be noted that education for sustainable development (ESD) is a unique and complicated process that has been the topic of a lot of research for the last few years. According to UNESCO ESD "empowers learners of all ages with the knowledge, skills, values and attitudes to address the interconnected global challenges we are facing, including climate change, environmental degradation, loss of biodiversity, poverty and inequality" [4]. It is stated that ESD embraces key topics focusing on environmental problems as well as citizenship, democracy and government, ethics, justice, human rights, peace, gender equality, responsibility etc. There are several special features combining the learning process and learning outcomes that ESD should have:

- be embedded in the curriculum in an interdisciplinary and holistic manner;

- share the values and principles of sustainable development;

- promote critical thinking, problem-solving and action to address challenges to sustainable development;

- employ a variety of educational methods to illustrate various processes;

- allow learners to participate in decision-making on the design and content of educational programmes;

- address local and global issues;

- look to the future ensuring that the content has long-term perspectives and uses medium and long-term planning [2].

It is claimed that the learning process embraces both what has been learned and what is learnt and includes all the participants of the process, namely learners, facilitators, coordinators, funders. Besides gaining knowledge, values and theories which refer to sustainable development, ESD learning also implies the development of the following abilities:

- ability to ask critical questions;

- ability to clarify one's own values;

- ability to envision positive and sustainable features;

- ability to think systematically;

- ability to respond through applied learning;

- ability to explore the dialectic between tradition and innovation [5].

Since ESD is considered to be holistic and transformational education that combines learning content, outcomes, pedagogy and learning environment, it integrates such contents as climate change, poverty, war and peace, global diseases, policy, sustainable consumption etc. into the curriculum, creating learner-centered teaching and learning settings. The main requirement of ESD is action-oriented pedagogy that is aimed at self-directed learning, cooperation, participation, problem-orientation, the connection of formal and informal learning as only these approaches are quite efficient for developing key competencies needed to promote sustainable development [6]. These competencies correlate with the above-mentioned abilities and include:

- systems thinking competency (the recognition and understanding of relationships; the analysis of complex systems);

- anticipatory competency (the evaluation of future activities; the application of the precautionary principle; the assessment of consequences, changes and risks);

- normative competency (the comprehension of norms and values; the negotiation of sustainability principles, goals, values in cases of conflicts and contradictions);

- strategic competency (the development and implementation of innovative actions for further sustainability at the local level);

- collaboration competency (the comprehension of other people's perspectives and actions; the facilitation of collaborative problem-solving);

- critical thinking competency (the reflection on one's own values, actions, opinions as well as other people's perceptions); 
- self-awareness competency (the reflection on one's own role in the local community and global society; the evaluation and motivation of one's actions);

- integrated problem-solving competency (the application of different problem-solving frameworks to complex sustainability problems and the development of viable, inclusive and equitable solution options that help promote sustainable development integrating the above-mentioned competencies) [ibid.].

To help learners achieve ESD goals and develop the key competencies various methods and tools might be used. One of such tools might be a foreign language in general and English in particular the role of which is significant at national and international levels. So it is really interesting to do research in this field focusing on learners' beliefs concerning the process of learning a foreign language, their willingness to communicate in L2 at language classes and ways to develop the above-mentioned competencies which are interconnected with soft skills.

\subsection{Soft skills and their importance}

The term "soft skills" is used to describe people skills that cover personality traits, habits, friendliness, optimism, ability to deal with problems etc. They play a crucial role in a person's life and especially profession. Thus, it is essential for language teachers to make learners acquire such skills. It is pointed out that the following skills can refer to the concept "soft skills":

- interpersonal skills (the ability to motivate, lead and delegate);

- teamwork (the ability to build a team and cooperate with its members in order to achieve goals);

- negotiation skills (the ability to achieve desired outcomes and get on well with people);

- communication skills (the ability to convey ideas to other people effectively);

- time management (the ability to prioritize tasks and manage time successfully especially when a person is overloaded);

- stress management (the ability to cope with stressful situations) [7].

According to another classification soft skills are divided into categories:

- social skills including communication and interpersonal skills as well as positive attitude, values, perception, etiquette;

- negotiating skills which relate to coping with time, stress, emotions and teamwork; and

- thinking skills which imply creativity, problem-solving and decision-making [ibid].

In addition to this, Gopalaswamy Ramesh et al. argue that soft skills constitute three dimensions: attitude, communication and etiquette. They can be considered to be essential for ESD targets as attitude embraces proper mental abilities and intentions to interact with people and environment; communication implies not only the simple act of exchanging ideas but also the act of conveying attitudes, convictions etc. in such a way that they will reach the intended audience and make them behave in accordance with the speaker's wishes; etiquette integrates norms and principles that must be followed to succeed in communication. In other words, attitude refers to the concept "want to do", communication - "what to do" and etiquette - "how to do" [8].

It is evident that sustainable development ideas and principles should be met by people living in different countries and consequently this fact may result in several challenges, such as: linguistic, cultural and the one connected with the increase in use of different media of communication and collaboration. For instance, people can use English to speak to the representatives of other countries as it is an international language but its usage is not the same in various parts of the world. Moreover, not everyone can speak English and it is also a problem. As for the cultural challenge, it underlines the diversity of cultures in different countries and the necessity to adapt to them if one wants to effectively 
communicate with other people, but this adaptation might take much time. And the third challenge implies the ability to apply technical skills and quickly orientate in the world of new technologies used for communication [ibid.]. To overcome these challenges it is necessary to develop soft skills.

Thus, it is noteworthy that soft skills no matter what category they belong to must be based on a strong and healthy attitude, positive evaluation of one's personality and the willingness to relate to the environment better. All this has a beneficial impact on the ability to either communicate, negotiate, work in a team or solve problems and think creatively. Therefore, language teachers should try to do their best to develop the above-mentioned qualities in students so that the latter can attain goals of both the learning process concerning a foreign language and ESD.

One more issue that must be taken into account in the process of developing soft skills in students by means of a foreign language is their willingness to communicate in this language.

\subsection{Willingness to communicate}

WTC in L2 is interpreted as "a readiness to enter into discourse at a particular time with a specific person or persons using an L2" [9]. This definition underpins the dual nature of WTC which implicates both one's traits of character as an essential part comprising WTC and dynamic behavior that depends on a specific situation. P. MacIntyre et al. analyzed those factors that effected a learner's WTC during the process of communication in L2 and presented a pyramid model which consists of six layers. The first layer is the use of L2, which is preceded by the second layer based on WTC and the third layer formed by the desire to communicate with a specific person and state communicative self-confidence. They are dominated by such factors as communication behaviour, behavioural intention and situated antecedents which refer to situational variables having an influence on L2 WTC at some particular moment. The fourth layer is based on interpersonal motivation, intergroup motivation, L2 self-confidence; the fifth layer is formed by intergroup attitude, social situation, communicative competence while the sixth layer encompasses intergroup climate and personality. These layers are effected by motivational propensities, affective-cognitive context and social and individual context which are considered to be stable and typical for any communication situation [ibid.].

It is clear that the pyramid demonstrates all stages that a learner must go through to master a foreign language, i.e. to use it effectively, therefore this is the top of the pyramid. However, to reach the top it is necessary to begin with every student's personality and the creation of the proper intergroup climate which are at the bottom of the pyramid. Only then a stage by stage combining personal ambitions, teamwork and motivation a language teacher can help a learner to approach the top where the last stage but one is WTC.

Since a learner's personality is of paramount importance in the process of learning a foreign language in general (that in its turn contributes greatly to achieving ESD goals) and developing WTC in particular, it is quite logical to find out more about students, especially their language beliefs and expectations at the starting point of the learning process.

\section{Methodology}

The aim of the research was to identify learners' beliefs and expectations concerning studying a foreign language at the beginning of the academic year in order to choose the most appropriate teaching strategies for developing soft skills, WTC in L2 within the framework of ESD. 
To do this we used a questionnaire as a research instrument which could help us ask the questions the answers to which interested us. To process the information received we applied a quantitative analysis to understand general attitudes of learners to the process of acquiring L2 and a qualitative analysis to gain in-depth comprehension of learners' expectations based on their personalities.

\subsection{Experimental part}

A survey was conducted among first-year students of Tambov State Technical University (TSTU), Russia. According to the curriculum, foreign language training at non-linguistic (engineering, economy, law) specialties is implemented at the first and second years two academic hours a week.

\subsubsection{Participants}

The research involved 100 first-year TSTU students doing their degree in Environmental Engineering who were asked to respond to the Language Learning Beliefs Questionnaire. The answers could vary from "strongly agree" to "strongly disagree".

\section{Results}

The questionnaire about students' language learning beliefs and expectations consists of 20 statements. The results are shown in Table 1.

Table 1. Language learning beliefs survey results.

\begin{tabular}{|l|c|c|c|c|c|}
\hline \multicolumn{1}{|c|}{ Questions } & $\begin{array}{c}\text { Strongly } \\
\text { agree } \\
\text { (st-s) }\end{array}$ & $\begin{array}{c}\text { Agree } \\
\text { (st-s) }\end{array}$ & $\begin{array}{c}\text { Neutral } \\
\text { (st-s) }\end{array}$ & $\begin{array}{c}\text { Disagree } \\
\text { (st-s) }\end{array}$ & $\begin{array}{c}\text { Strongly } \\
\text { disagree } \\
\text { (st-s) }\end{array}$ \\
\hline $\begin{array}{l}\text { 1. It is difficult for people over 40 to learn } \\
\text { a foreign language }\end{array}$ & 12 & 58 & 0 & 30 & 0 \\
\hline $\begin{array}{l}\text { 2. It is necessary to have a special } \\
\text { aptitude to learn a language well }\end{array}$ & 0 & 51 & 39 & 10 & 0 \\
\hline $\begin{array}{l}\text { 3. It's important to have your errors } \\
\text { corrected from the start }\end{array}$ & 83 & 7 & 0 & 0 & 10 \\
\hline $\begin{array}{l}\text { 4. Grammar drills are very important in } \\
\text { mastering a foreign language }\end{array}$ & 58 & 42 & 0 & 0 & 0 \\
\hline $\begin{array}{l}\text { 5. It is easier to learn a foreign language } \\
\text { if you like native speakers }\end{array}$ & 27 & 62 & 11 & 0 & 0 \\
\hline $\begin{array}{l}\text { 6. The best way to learn a language is just } \\
\text { spending time with people who speak this } \\
\text { language }\end{array}$ & 0 & 18 & 31 & 41 & 10 \\
\hline $\begin{array}{l}\text { 7. You shouldn't speak a new language as } \\
\text { long as you make mistakes }\end{array}$ & 0 & 0 & 13 & 48 & 39 \\
\hline $\begin{array}{l}\text { 8. Learning a foreign language is a key to } \\
\text { a successful career }\end{array}$ & 26 & 54 & 13 & 7 & 0 \\
\hline $\begin{array}{l}\text { 9. It is important to repeat and practice a } \\
\text { lot }\end{array}$ & 84 & 16 & 0 & 0 & 0 \\
\hline $\begin{array}{l}\text { 10. You will be able to speak a language } \\
\text { well if you understand how it works }\end{array}$ & 41 & 47 & 12 & 0 & 0 \\
\hline $\begin{array}{l}\text { 11. Team or group work is important } \\
\text { while studying a foreign language }\end{array}$ & 21 & 69 & 10 & 0 & 0 \\
\hline $\begin{array}{l}\text { 12. Learning a foreign language helps to } \\
\text { solve different kinds of problems }\end{array}$ & 23 & 67 & 10 & 0 & 0 \\
\hline
\end{tabular}




\begin{tabular}{|l|c|c|c|c|c|}
$\begin{array}{l}\text { 13. It is necessary to get and provide } \\
\text { feedback at foreign language lessons }\end{array}$ & 42 & 48 & 0 & 10 & 0 \\
\hline $\begin{array}{l}\text { 14. Individual work is much more } \\
\text { effective than collaboration }\end{array}$ & 0 & 8 & 13 & 52 & 27 \\
\hline $\begin{array}{l}\text { 15. Project work is useless while learning } \\
\text { a foreign language }\end{array}$ & 0 & 0 & 20 & 51 & 29 \\
\hline $\begin{array}{l}\text { 16. It is important to become a leader of a } \\
\text { group when you study a foreign language }\end{array}$ & 17 & 43 & 21 & 9 & 10 \\
\hline $\begin{array}{l}\text { 17. Getting acquainted with culture is } \\
\text { essential in language learning }\end{array}$ & 73 & 27 & 0 & 0 & 0 \\
\hline $\begin{array}{l}\text { 18. Spending a year or so in a foreign } \\
\text { country will help you become fluent in a } \\
\text { language }\end{array}$ & 0 & 84 & 16 & 0 & 0 \\
\hline $\begin{array}{l}\text { 19. It is important to listen a lot before } \\
\text { starting to speak }\end{array}$ & 51 & 29 & 7 & 13 & 0 \\
\hline $\begin{array}{l}\text { 20. Anxiety interferes with language } \\
\text { learning }\end{array}$ & 14 & 56 & 20 & 0 & 0 \\
\hline
\end{tabular}

(1) According to the survey, $70 \%$ of the respondents admit that it is easier to learn a foreign language at a younger age; therefore, they expect to learn a foreign language faster and at a higher level due to their age.

(2) The questionnaire statement about the relevance of having a special aptitude for mastering a foreign language aroused doubts among students with $39 \%$ of the respondents staying neutral. This dubious reaction suggests that students are not aware of their own language aptitude; hence, the teacher should develop students' self-confidence not to be afraid of communication failures and mistakes. In this regard, an individual approach to students can be realized while designing a lesson plan.

(3-7) The statement about the importance of error correction is supported by most of the respondents, which is actually surprising as students do not like being corrected all the time. In order not to discourage students, it seems effective to partially correct mistakes made by less confident students or do it in the form of self-correction analysis, thus developing critical thinking skills.

(4), (9-10) Concerning grammar drills, understanding language structures and practising, all students showed consistent results that doing grammar exercises and understanding how the language works is necessary for improving their language proficiency. However, it should be noted that grammar rules are better acquired when they are incorporated into different types of communicative tasks so that students may not even notice they are practising grammar.

(5-6) The connection of easy language learning with the positive attitude to native speakers was supported by the respondents which can be explained by the students' frequent communication with natives in and out of the classroom (natives are often invited to the lessons and special events such as language quests, quizzes, competitions, etc.). However, half of the students agreed that clear lesson organization and setting lesson goals cannot be neglected.

(8) $80 \%$ of the respondents agree that learning a foreign language brings plenty of opportunities in terms of professional development. In this connection, the ESP course done during the second year is viewed as a necessary element in the process of becoming a highly-qualified specialist.

(11), (14) $90 \%$ of the students consider team or group work an important part of the language learning process as this type of working develops cooperation, social skills and encourages weaker students to catch up with the stronger ones. Moreover, collaboration contributes to the students' own language and professional expertise and benefits of a shared project. 
(12) The statement about problem-solving skills developed at the foreign language lessons is supported by $90 \%$ of the respondents. In a problem based learning classroom teachers act as coaches discussing the ideas with students, making up decisions and practicing different forms of behavior. Thus, the emphasis in the learning process moves from the language training to developing real communication skills.

(13) The necessity of getting and providing feedback at foreign language lessons is marked by $90 \%$ of the respondents. Students need feedback in order to consolidate their learning outcomes; however, it should be received in time to make use of it. Providing feedback on other students' work is also important as students learn to assess and criticize other people's work.

(15) $80 \%$ of the students regard project work as a useful part in learning a foreign language. The teaching experience shows that students engaged in the project work (making presentations on professional topics, portfolios, etc.) show high motivation and willingness to communicate.

(16) The answers to the statement about the importance of being a leader in a foreign language group are distributed across all categories. During classroom teamwork, roles are usually assigned by the teacher, and strong students inevitably become leaders. In this case, we are talking about the development of such a skill as leadership.

(17) All the respondents agree that it is impossible to learn a foreign language without getting acquainted with its culture. Realizing the national peculiarities in different cultures should be a part of international communication, without which it is impossible to become a professional.

(18) $84 \%$ of the respondents think that the atmosphere of a foreign country makes people speak the local language fluently. However, it is possible to create this kind of "immersion" atmosphere in the classroom through using authentic video, audio, or reading material.

(19) The statement concerning the importance of listening a lot before starting to speak was supported by $80 \%$ of the respondents, though integrated tasks, where both listening and speaking skills are engaged, show greater productivity.

(20) The last statement about the bad effect of being anxious when learning a foreign language was supported by $70 \%$ of the respondents. The way out to reduce stress at the lesson is to create a positive atmosphere for the students without being afraid to expressing their points of view in a foreign language or making mistakes.

\section{Discussion}

The analysis of the survey results showed that first-year students have the high or aboveaverage level of their language learning beliefs at the start of the foreign language training at the university. These findings allowed us to design a foreign language course involving effective teaching strategies to meet students' language learning beliefs and expectations.

The course, which is intended for environmental engineering students, consists of two parts - General English (first year) and ESP (second-year). At the first year students improve their overall level of English and hone their communication skills, while at the second year they immerse themselves in the professional sphere of communication through reading authentic articles, writing reports, watching videos and preparing projects on the burning environmental issues.

Since foreign language training includes not only language learning itself but presupposes a multifaceted development of the student's personality, it is clear that the effective foreign language course should train a specialist who is successful in terms of negotiations, cooperation and communication in general. While designing the course for environmental engineering students we paid attention to forming and developing flexible 
soft skills for ESD purposes in accordance with students' attitudes. Let us focus on how these skills are implemented in the foreign language training.

Communication skills. Undoubtedly, hardly any foreign language course can do without the development of communication skills as the final goal of the language learning is free communication in a foreign language. Any language assignment includes practising four core communication skills, i.e. listening, reading, speaking, and writing.

Teamwork skills. This kind of skills is incorporated into the course in the form of group or team assignments such as discussions, debates, round tables, projects, negotiations, etc. giving students the opportunity to function in collaboration with each other and find effective solutions born in group discussions. Among the tasks developing teamwork skills are: discussing waste treatment technologies in groups and make a joint report; analyzing environmental situation in different countries in the round table discussion and preparing a comparative analysis, etc. However, it is necessary for the teacher to distribute roles in such a way that learners can cope with them according to their level of language proficiency.

Presentation skills are inextricably linked with teamwork skills as the tasks in the course are usually aimed at developing several skills at a time. For example, the task to assess environmental impacts associated with car manufacturing and to work out effective strategies of reducing bad impact on the environment contributes to developing both teamwork, problem-solving, critical thinking and presentation skills. The assignment to make a presentation about a particular natural phenomenon, environmental problem or ways of recycling waste is an effective activity, where both students' language skills (vocabulary, grammar, reading, listening) and soft skills (working with visual aids, providing feedback on the performance, discussing weak and strong points of presenting the material) are trained.

Negotiation skills which are closely connected with critical thinking and problemsolving skills are very important to develop in future specialists in order to teach them how to resolve conflicts. The teaching strategy is usually realized through the group work with the topics given beforehand for the students to get ready with the ideas. Before the meeting itself, the key negotiating points (negotiating behaviour and strategies, ways of agreement/disagreement) should be discussed. Negotiations are monitored by the teacher helping elicit new ideas and manage the time. The final stage is characterized by students' feedback and discussing the strengths and weaknesses of the negotiation process.

Leadership skills are usually realized through analyzing and discussing team roles while doing group projects, case studies or role-playing. In the process of work, groups are trained to maintain constructive relationships, conduct a dialogue, regulate conflicts, and find a compromise which helps remove students' anxiety and build confidence in using the foreign language. Indeed, one of the objectives in developing leadership skills is establishing students' confidence, the ability to quickly navigate in a large flow of information and see the main things.

Time-management skills are developed in the course through tasks where tight timing is important to follow. For example, students are given the task to express their point of view on the most dangerous environmental problem and give compelling reasons to prove their opinion in 5 minutes. The aim of such tasks is to teach students how to manage their time properly in order to do more things in less time since a developed time-management skill is one of the hallmarks of a good specialist.

Intercultural skills are realized in the course through authentic materials (texts, video, audio) which add to students' intercultural awareness, keep them motivated and develop cross-disciplinary relations. Studying the history of environmental engineering, discussing various environmental problems in different regions contribute to constructing students' cultural identity. Through comparison of domestic and foreign environmental technologies, role-playing, talk shows students reconstruct and assess a foreign culture perspective. 
Thus, most of the soft skills are interconnected with each other and usually present in one task. The course for environmental engineers includes plenty of tasks aimed at developing soft skills which help students learn how to solve problems of sustainable development and construct various scenarios for the future. Successful teaching strategies involve situations where students learn how to succeed in negotiations, give arguments, properly manage their time, and build effective communication with international partners. Mastering soft skills contributes to students' willingness to communicate in terms of second language acquisition and helps develop the language, strategic, sociocultural, discourse, pragmatic and other related competencies.

\section{Conclusion}

Taking into considaretion the survey results on students' language learning beliefs and expectations at the preliminary stage, we can assume that the students wish to learn a foreign language. According to the findings, we designed the course for environmental engineering students aimed at developing not only vital language skills, but also soft skills which help students navigate in the modern professional community and realize themselves as highly-qualified specialists able to communicate at an international level.

Following students' high language learning beliefs, the developed course focuses on the most efficient teaching strategies reflecting students' expectations, developing their professionally oriented communication skills, cultivating soft skills for ESD purposes, and increasing their willingness to communicate in a foreign language. Knowledge of students' learning beliefs may help the teacher select the educational material and adapt teaching strategies to satisfy students' needs and opportunities.

This research is to be further continued in order to see if the students' language learning beliefs are satisfied after completing the course. It would be interesting to compare the survey results at the start and the end of the course for its improvement and supplement according to the students' expectations.

\section{References}

1. G. Brundtland (ed.), Our Common Future: The World Commission on Environment and Development, 43 (1987)

2. E. Nevin, Pol. and prac.: ESD, 6, 49 (2008)

3. Education for sustainable development sourcebook (UNESCO, 2012)

4. Education for sustainable development, available from: https://en.unesco.org/themes/education-sustainable-development

5. Education for sustainable development. An expert review of processes and learning (UNESCO, 2011)

6. Education for sustainable development goals: learning objectives (UNESCO, 2017)

7. K. Alex, Soft skills: know yourself and know the world (2009)

8. G. Ramesh, M. Ramesh, The ace of soft skills: attitude, communication and etiquette for success (2010)

9. P.D. MacIntyre, Z. Dörnyei, R. Clément, K.A. Noels, The Mod. Lang. J., 82(4), 547 (1998)

10. T. Yashima, The Mod. Lang. J., 86(1) (2002)

11. Z. Zarrinabadi, Syst., 42(1) (2014) 